\title{
Por uma interpretação concreta: simbolismo, decifração e contextualização nos sonhos
}

\author{
For a concrete interpretation: symbolism, \\ deciphering and contextualization in dreams
}

\section{Suely Aires}

Professora assistente da Universidade Federal do Recôncavo Baiano (UFRB), Salvador, BA - Brasil, e-mail: suely.aires7@gmail.com

\section{Resumo}

Em sua obra mais famosa, Traumdeutung (1900), Sigmund Freud apresenta os sonhos como processos psíquicos de caráter múltiplo que se constituem como conglomerados de formações psíquicas. Ainda nesse texto, afirma que os sonhos fazem parte de uma atividade complexa da mente e podem ser inseridos na cadeia de atos mentais inteligíveis da vigília. Conclui, nessa direção, que os sonhos são fenômenos psíquicos válidos, o que implica a ampliação do campo dos fatos reconhecidos como tais pela ciência psicológica. Posteriormente, Freud fará o mesmo em relação às parapraxias e aos lapsos de memória, bem como em relação aos chistes, constituindo uma psicopatologia da vida cotidiana que inaugura um novo campo para os fatos psicológicos. Após essa proposição, faz-se necessário, para a constituição da psicanálise, discutir o método de abordagem desses 
fenômenos. Neste artigo, propomo-nos apresentar os modos de interpretação onírica na teoria freudiana em sua relação com o relato. Para tanto, acompanhamos o desenrolar argumentativo da obra freudiana A Interpretação dos Sonhos (1900) e buscamos isolar elementos que permitem indicar um dado modo de construção e endereçamento ao leitor. Nesse percurso, o leitor é incluído e se faz incluir na obra, tanto em sua condição de sonhador, quanto na posição de intérprete e de censor dos sonhos.

Palavras-chave: Sonhos. Interpretação. Freud.

\section{Abstract}

In his most famous work, Traumdeutung (1900), Sigmund Freud presents dreams as psychic processes of multiple character, as conglomerates of psychical formations. In this paper, he states that dreams are part of a complex activity of mind and can be inserted in the chain of intelligible waking mental acts. This author concludes, in this direction, that dreams are valid psychic phenomena, which implies broader facts recognized as such by psychological science. Later, Freud will do the same with the parapraxes and lapses of memory, as well as for jokes, being a psychopathology of everyday life that opens a new field to the psychological facts. Following this proposition, it is necessary for the creation of psychoanalysis, discussing the method of approach to these phenomena. In this paper we propose to present the ways to onirical interpretation in relation to its narrative in freudian theory. In order to accomplish that, we follow the argumentative development of the Freudian work The interpretation of dreams (1900) by seeking to isolate the elements which allow us to ways of construction and addressing the reader. Along this course, the reader is included and makes himself to be included in the work, as a dreamer, both in the position of interpreter and censor of dreams.

Keywords: Dreams. Interpretation. Freud.

A interpretação dos sonhos de Freud não se restringe a sonhos. É uma autobiografia ao mesmo tempo sincera e cautelosa, tão instigante pelo que revela quanto pelo que omite. Mesmo na primeira edição, mais breve do que as que se sucederam, ela oferece um levantamento das ideias psicanalíticas fundamentais [...]. Ela apresenta, um tanto de passagem, nítidos esboços do mundo médico vienense, repleto de rivalidades e de caçadores de prestígio, e da sociedade austríaca, infectada pelo antissemitismo e no final de suas décadas liberais (GAY, 1989, p. 109-110). 
Nessa breve referência ao texto freudiano, Peter Gay destaca três aspectos da interpretação dos sonhos: o autobiográfico, o teórico, o circunstancial. Esses aspectos guiarão este artigo em uma separação que poderíamos dizer arbitrária, já que tais elementos estão de tal forma próximos que se torna impossível destacar o aspecto propriamente teórico daquilo que se pode chamar de formulações contextuais. As separações construídas e que dão nome aos subtópicos do presente texto visam apenas a acompanhar a obra freudiana $A$ interpretação dos sonhos (1900) em seu desenrolar argumentativo e isolar elementos que permitam indicar um dado modo de construção e endereçamento da obra ao leitor. Em nosso percurso, as citações cumprirão o papel de pontos de apoio material para evidenciar um estilo de construção textual.

\section{Do livro}

Ao referir-se à escrita da Traumdeutung, Freud relaciona o livro ao momento vivenciado e à significação construída a posteriori, contextualizando não apenas a sua posição como autor, como também indicando sua condição de sonhador, aquele cujos sonhos serão analisados ao longo da obra.

[...] este livro tem para mim pessoalmente outro significado subjetivo um significado que somente aprendi após tê-lo concluído. Foi, assim verifiquei, uma parcela de minha própria auto-análise, minha reação à morte de meu pai - isto é, ao evento mais importante, à perda mais pungente, da vida de um homem. Tendo descoberto que assim foi senti-me incapaz de obliterar os vestígios da experiência. Aos meus leitores, contudo, será assunto de indiferença sobre qual material específico eles aprenderão a apreciar a importância dos sonhos e como interpretá-los (FREUD, [1900] 1977, p. 34).

Cabe ainda destacar que, nas palavras de Freud, o texto de 1900 tem uma significação subjetiva que é comum e compartilhável com outros homens - a perda de um pai - e que, em sua singularidade, apresenta-se como material científico. Ao mesmo tempo, ainda na 
perspectiva freudiana, pode-se retirar essa dimensão pessoal sem prejuízo da argumentação sustentada ao longo das numerosas páginas, argumentação que se pretende universal, na condição de que sua vida possa ser vista como a vida do homem comum. Desse modo, Freud justifica a escolha do material a ser analisado, e a psicanálise, como método de análise, é incluída na vida cotidiana dos homens e não se mostra útil apenas para a prática clínica com neuróticos.

Tornar-se-á simples, no decurso da própria obra, o motivo por que nenhum dos sonhos já relatados na literatura do assunto ou coligido de fontes desconhecidas poderia ser de qualquer utilidade para meus propósitos. Os únicos sonhos abertos à minha escolha foram os meus próprios e os de pacientes submetidos a tratamento psicanalítico. Mas fui impedido de utilizar o segundo material pelo fato de que, nesse caso, os processos oníricos estavam sujeitos a uma compilação indesejável em vista da presença adicional de características neuróticas. Mas se eu quisesse relatar meus próprios sonhos, inevitavelmente se inferiria que deveria revelar ao público maior número de aspectos íntimos de minha vida mental do que desejaria, ou do que é normalmente necessário para qualquer escritor que seja um homem de ciência e não um poeta. Tal foi a penosa mas inevitável necessidade, e me submeti à mesma ao invés de abandonar totalmente a possibilidade de apresentar evidências para os meus achados psicológicos. Naturalmente, contudo, não pude resistir à tentação de aparar as arestas de algumas de minhas indiscrições por omissões e substituições. Mas sempre que isso aconteceu, o valor de meus exemplos se viu reduzido de forma bem categórica. Posso apenas manifestar a esperança de que os leitores deste livro coloquem-se em minha difícil situação e me tratem com indulgência [...] (FREUD, [1900] 1977, p. 31-32).

Contudo, essa escolha implica uma contextualização da própria vida que pode vir a gerar constrangimentos e Freud dirige-se ao leitor sob três modos que nos parece interessante destacar: (1) a assunção das omissões e substituições produzidas sobre o texto dos sonhos, como escolha do autor/sonhador Freud, (2) seu pedido para que o leitor seja indulgente com ele, Freud, e (3) o convite - mais uma vez feito ao leitor - para que este se coloque em sua posição, de intérprete. Poderíamos completar: colocar-se em posição de intérprete também em relação aos próprios 
sonhos. As posições de autor, sonhador e leitor apresentam, por conseguinte, uma mobilidade que indicam o caminho a ser trilhado.

\section{Escritor, leitor, censor: posições do sujeito na Traumdeutung}

Cabe deixar claro que supomos - e pretendemos argumentar isso ao longo deste texto - que a interpretação freudiana dos sonhos, para ser levada a cabo, necessariamente implica a inclusão de elementos de contextualização dos sonhos que podem ser fornecidos unicamente pelo sonhador em sua relação ao meio cultural e linguístico, em sua cotidianidade, o que justificaria a primeira frase de Freud nessa longa citação: “Tornar-se-á simples, no decurso da própria obra, o motivo por que nenhum dos sonhos já relatados na literatura do assunto ou coligido de fontes desconhecidas poderia ser de qualquer utilidade para meus propósitos". O escritor/sonhador Freud, o leitor/intérprete de sonhos e o censor/Freud diante do leitor/censor constroem um percurso que se pretende científico. Nesse sentido, torna-se possível seguir a aposta freudiana e

[...] presumir que meus leitores também muito cedo encontrarão seu interesse inicial nas indiscrições que estou destinado a fazer substituídas por uma imersão absorvente nos problemas psicológicos sobre os quais lançam luz. Em consequência, passarei a escolher um de meus próprios sonhos e demonstrarei, à base dele, meu método de interpretação. No caso de todo sonho dessa natureza, far-se-ão necessárias algumas observações à guisa de preâmbulo. - Agora devo pedir ao leitor que faça dos meus interesses os seus próprios por um período bastante longo, e mergulhe, juntamente comigo, nos menores detalhes de minha vida, porquanto uma transferência dessa natureza é peremptoriamente exigida por nosso interesse no significado oculto dos sonhos (FREUD, [1900] 1977, p. 113).

Atentem que, desde a particularidade de seus sonhos, Freud convida o leitor a passear pela generalidade científica de um método de interpretação. Trata-se do capítulo II - O método de interpretação dos 
sonhos: a análise de um sonho modelo [sonho da injeção de Irma] - trecho do trabalho da Traumdeutung no qual a interpretação freudiana dos sonhos necessita ser diferenciada dos modos clássicos de interpretação onírica - o simbolismo e a decifração - a fim de se constituir como um procedimento que não se confunda com as práticas religiosas e de crença popular.

Ainda nesse capítulo, a fim de defender a especificidade de seu método, Freud apresenta e opõe os dois modos clássicos de interpretação dos sonhos: de um lado, considera que a interpretação simbólica toma o sonho como um todo, assemelhando-se à arte, pois depende de dons particulares do intérprete; por outro lado, afirma que a interpretação por decifração tem como modelo a criptografia, tomando os elementos do sonho de forma isolada e segundo uma chave fixa de leitura. Embora busque diferenciar seu método mais claramente do procedimento interpretativo simbólico, Freud utiliza ambos os modos de interpretação onírica para construir o método psicanalítico de interpretação de sonhos. No entanto, um ponto, a nosso ver, não é suficientemente enfatizado pelo autor: trata-se da contextualização do sonho por parte do sonhador que, ao colocar sob a forma de relato seu produto onírico, necessariamente o faz mediante associação com outros elementos da vida psíquica, de tal modo que a contextualização do sonho se constrói durante a narrativa do agente por meio de referências que unem particular e social, narrativa feita para um outro.

\section{Endereçamento}

Para os conhecedores de Freud, é fácil identificar o recurso ao leitor colaborativo ou cético suposto como personagem dentro do texto, aquele que Freud conduz pela mão em um passeio pela argumentação a ser construída. Nesse contexto, Freud antecipa as críticas que serão formuladas, apresenta perguntas que permitem um esclarecimento de seu ponto de vista e supõe um outro que não é indiferente aos seus argumentos. Trata-se de uma estratégia de sedução, 
poderíamos dizer, de desvio para um caminho que permite ao leitor considerar o argumento freudiano desde uma perspectiva inclusiva. No caso específico da Traumdeutung, o leitor é incluído, dentre outros aspectos, ao considerar os próprios sonhos - já que todos sonham bem como ao admitir, ainda que temporariamente, a hipótese de que o sonho é um produto psíquico prenhe de sentido e que, portanto, pode vir a ser interpretado.

Quando, depois de passarmos por um estreito desfiladeiro, de súbito, damos com um trecho de um terreno elevado, onde o caminho se divide e as mais belas vistas se desdobram por todos os lados, podemos parar por um momento e considerar em que direção devemos primeiramente orientar nossos passos. Tal ocorre conosco, agora que ultrapassamos a primeira interpretação de um sonho. Encontramo-nos em plena luz de uma súbita descoberta [...].

Porém, mal começamos a nos regozijar com essa descoberta, e já somos assaltados por uma torrente de questões. Se, como somos informados pela interpretação de sonhos, um sonho representa um desejo realizado, qual a origem da notável e enigmática forma em que a realização de um desejo é expressa? Por que alteração passaram os pensamentos oníricos antes de se transformarem no sonho manifesto que recordamos ao despertar? Como se verifica essa alteração? Qual a fonte do material que se modificou, transformando-se no sonho? Qual a fonte das numerosas peculiaridades que devem ser observadas nos pensamentos oníricos - tais como, por exemplo, o fato de poderem ser contraditórias? [...]. Pode um sonho dizer-nos algo de novo sobre nossos processos psíquicos internos? Pode seu conteúdo corrigir opiniões que mantivemos durante o dia?

Proponho que, no momento, deixemos todas essas questões de lado e prossigamos ao longo de uma trilha particular (FREUD, [1900] 1977, p. 131-132).

E eis que a trilha segue, a condução freudiana do leitor o leva a novos passos e capítulos e um novo argumento se apresenta como proposição central do edifício freudiano: o sonho é a realização de um desejo - argumento explicitado ao longo do capítulo III. O tópico seguinte $-A$ distorção dos sonhos, capítulo IV - constitui-se em momento 
em que Freud dá ao leitor uma posição radicalmente cética ${ }^{1}$ e o inclui diretamente em sua narrativa.

Se passar a fazer a assertiva de que o significado de que todo sonho é a realização de um desejo, isto é, que não pode haver quaisquer sonhos, a não ser sonhos impregnados de desejos, sei antecipadamente que me confrontarei com a contradição mais categórica (FREUD, [1900] 1977, p. 143).

Freud continua com um longo parágrafo entre aspas, posição suposta ao leitor de incredulidade crítica diante do texto. Ao prosseguir e considerar o tema de base desse capítulo - a relação entre conteúdo manifesto e conteúdo latente - Freud defende mais uma vez o argumento central da interpretação dos sonhos, acrescentando, nesse momento, um adjetivo. O sonho é uma realização disfarçada de desejo. Aqui Freud toma alguns exemplos interessantes (Cf. FREUD, [1900] 1977, p. 156-172). Nesse contexto, o leitor ou o paciente que sonha algo que aparentemente destoa da afirmação geral sobre a natureza dos sonhos coloca-se na condição de quem deseja mostrar que Freud está errado, reafirmando o que parecia negar.

Se antes, no companheirismo diante das paisagens do sonho, o leitor era colocado transferencialmente ao lado do narrador e Freud pode se endereçar ao leitor, nesse momento, a resistência do leitor diante do argumento freudiano reafirma a teoria freudiana ao supor um endereçamento do leitor a Freud. Contudo, cabe destacar que esse endereçamento não se faz de forma transparente, mútua ou mesmo dialética. Em determinados trechos, Freud supõe um leitor ávido por novas informações, por vezes curioso, por vezes resistente. A novidade de supor um

1 Acompanhemos o trecho em que Freud se coloca na condição de incrédulo e indica que suprimiu determinadas partes do sonho. "Quando, no decorrer da manhã, o sonho me veio à cabeça, ri alto e disse: '0 sonho é uma bobagem!' Mas ele se recusava a ir embora e me seguiu o dia inteiro, até que, finalmente, à tardinha, comecei a repreender-me: 'Se um de seus pacientes que estivesse interpretando um sonho não pudesse ter nada melhor para dizer do que era bobagem, essa pessoa seria censurada a esse respeito e suspeitaria que o sonho apresentava algo desagradável e que ela queria evitar tornar-se cônscia desse fato. Proceda consigo mesmo da mesma maneira. Sua opinião de que o sonho é bobagem somente significa que você tem uma resistência interna contra sua interpretação. Não se deixe despistar dessa maneira.' Assim, dei início à interpretação" (FREUD, [1900] 1977, p. 147, grifo nosso).

Rev. Filos., Aurora, Curitiba, v. 23, n. 33, p. 301-314, jul./dez. 2011 
endereçamento do leitor ao autor, em uma posição cética ou de desconfiança, foi o que permitiu a aproximação proposta por alguns autores (FOUCAULT, 2000; RICOEUR, 1965; BORGES, [19--]; GINZBURG, 1990) entre o método clínico psicanalítico, a suspeita como condição prévia à leitura e os romances policiais.

Ora, a suspeita prévia em relação ao material apresentado - no caso, os sonhos - elide a clareza do posicionamento do leitor como intérprete de um signo exterior a si: se não há coincidência entre a aparência e a realidade, será necessário construir uma técnica interpretativa que busque decifrar o sentido dessa produção humana particular, o sonho. Essa interpretação, no entanto, só pode vir a ser realizada pelo sonhador - ou seja, o leitor - e, ainda assim, ao colocar em suspeição sua própria interpretação, ao considerar a existência de uma censura psíquica, também apresentada por Freud nesse capítulo e que discutiremos a seguir. Cabe ainda considerar uma outra possibilidade, posição na qual o leitor não suspeita e apenas confia e se deixa conduzir por Freud na interpretação realizada em relação aos próprios sonhos, de Freud, que, diga-se de passagem, são inacessíveis ao leitor.

\section{Da censura: conteúdo manifesto e conteúdo latente}

A interpretação freudiana dos sonhos apoia-se sobre a ideia de que esses produtos psíquicos são significações complexas que não se mostram como tais numa primeira aproximação, mas que podem ser reveladas após o uso da técnica analítica. Ou seja, outro sentido se oculta sob o sentido mais evidente - o conteúdo manifesto surge como uma distorção do conteúdo latente. Ao buscar a significação dos termos da narrativa do sonho, a psicanálise o toma como um texto a ser decifrado, o qual pode ser enunciado de forma clara ou verdadeira se o sonhador fizer uso de signos mais adequados a suas intenções significativas. Assim, o relato do sonho, tal como dado pelo sonhador, em que as intenções significativas estão disfarçadas, pode ser substituído por outro, no qual estas aparecem com seus signos apropriados para enunciar o desejo inconsciente mobilizador do sonho. Destaquemos, 
desse capítulo, a analogia entre o mecanismo da deformação onírica e a censura política a livros já editados.

Os delírios são obra de uma censura que não mais se dá ao trabalho de ocultar o seu funcionamento; em vez de colaborar na produção de uma nova versão que seja inobjetável, ela brutalmente apaga aquilo que desaprova, de maneira que o que sobra se torna bastante desconexo. Esta censura atua exatamente como a censura de jornais na fronteira russa, que só permite aos periódicos estrangeiros chegar às mãos dos leitores após uma certa quantidade de trechos haver sido suprimida (FREUD, [1900] 1977, p. 564-565).

Já em 1937, Freud retoma a analogia - mais uma vez para explicitar o funcionamento da censura - e a enriquece por meio de algumas nuances.

Imaginemos o que poderia ter acontecido a um livro, numa época em que os livros ainda não eram impressos em edições, mas redigidos individualmente. Suponhamos que um livro desses contivesse afirmações que, em épocas posteriores, fossem consideradas indesejáveis [...]. Nos dias de hoje, o único mecanismo defensivo de que a censura oficial poderia valer-se seria o de confiscar e destruir todos os exemplares da edição inteira. Naquela época, contudo, diversos métodos eram utilizados para tornar inócuo o livro. Uma das maneiras seria riscar cerradamente as passagens ofensivas, de modo a ficarem ilegíveis. Nesse caso, elas não poderiam ser transcritas, e o copista seguinte do livro produziria um texto inatacável, mas com lacunas em certas passagens, e, assim, nestas ele poderia ser ininteligível. Outra maneira, contudo, se as autoridades não se satisfizessem com isso, mas desejassem ocultar também qualquer indicação de que o texto fora mutilado, seria, para elas, passar a deformar o texto. Palavras isoladas seriam deixadas de fora ou substituídas por outras, e novas frases seriam interpoladas. Melhor do que tudo, toda a passagem seria apagada e colocada em seu lugar outras novas dizendo exatamente o oposto. $\mathrm{O}$ transcritor seguinte poderia então produzir um texto que não despertaria suspeita, mas que seria falsificado. Ele não mais conteria o que o autor desejara dizer, no sentido da verdade (FREUD, [1937] 1977, p. 269).

Essa analogia parece ter por função no texto freudiano explorar a ideia de que os delírios e os sonhos, mesmo os mais desconexos, têm 
uma significação oculta sob suas distorções, ponto já desenvolvido anteriormente. No entanto, um dos possíveis efeitos dessa analogia é a suposição de que, se conseguíssemos apagar os riscos e pudéssemos ter acesso às supressões e/ou alterações, nos encontraríamos diante do texto original. Aqui há um texto, um autor, e um intérprete que, diante desse texto, encontra o autor mais verdadeiro. Mas esse não é o argumento freudiano. Para Freud, a censura psíquica agiria no próprio momento de construção do sonho, não sendo um efeito posterior do mecanismo de repressão sobre um sonho já sonhado. Se considerarmos, então, o endereçamento da escrita, da produção onírica, veremos que a censura incide não apenas na produção das imagens ou na transcrição das imagens do sonho em palavras, pois implica também a narrativa para um outro, suposto leitor. No texto de 1900, Freud, diante do leitor, censura conteúdos e afirma a perda na possibilidade de interpretação dos sonhos.

Os capítulos V - O material e as fontes dos sonhos - e VI - O trabatho do sonho - dão continuidade aos argumentos sobre os mecanismos formadores do sonho. Condensação e deslocamento são os elementos mais frequentemente debatidos, mas gostaria de chamar a atenção para a preocupação com a representabilidade e a elaboração secundária, aspectos pouco explorados nas discussões posteriores sobre os sonhos. Tanto a preocupação com a representabilidade quanto a elaboração secundária lançam para primeiro plano o caráter narrativo do sonho, pois tem como finalidade a produção de um produto psíquico com forma pictórica e concreta que pode vir a ser representado em um conteúdo minimamente coerente.

\section{Da contextualização}

Chegamos ao ponto central de nossa argumentação: ao circunstanciar o sonho, ao colocar sob a forma de relato seu produto onírico, o sonhador necessariamente o faz mediante associação com outros elementos da vida psíquica, de tal modo que a contextualização do sonho se constrói durante a narrativa do agente por meio de referências que unem particular e social. O capítulo VII - A psicologia dos processos 
oníricos -, que se constitui em suporte metapsicológico para as construções freudianas, mostra-se como o contraponto teórico do que buscamos desenvolver. Ao considerar esse capítulo, o leitor é levado a mudar os rumos de seu percurso, conduzido pelo próprio Freud.

Até aqui, estivemos principalmente interessados no significado secreto dos sonhos e no método de descobri-los, bem como nos meios empregados pela elaboração onírica para ocultá-lo: os problemas da interpretação onírica ocuparam o centro do quadro. (...) Somente após havermos resolvido tudo aquilo que se relaciona com o trabalho de interpretação é que poderemos começar a compreender as deficiências de nossa psicologia de sonhos.Entretanto, antes de partirmos por esse novo caminho, será bom fazer uma pausa e olhar em torno, para ver se, no decurso de nossa jornada até aqui, desprezamos alguma coisa de importância. Porque deve ficar claramente entendido que a parte fácil e agradável de nossa viagem ficou para trás (FREUD, [1900] 1977, p. 544-545).

É a teoria metapsicológica que se apresenta como ponto de esquecimento ou, melhor dito, ponto que merece ser claramente apresentado ao leitor, e que até o momento não foi elucidado. Mas por que uma aparição tão tardia da argumentação metapsicológica, após seis capítulos plenos de exemplos que já apresentam o método interpretativo freudiano? Se tomarmos o texto freudiano tendo como pano de fundo a crítica politzeriana à psicologia (Cf. POLITZER, 1998), podemos considerar que não se faz necessário realizar um estudo abstrato e formal dos elementos oníricos. Pode-se encontrar no método freudiano um sujeito imerso em uma vida composta de acontecimentos particulares e situado historicamente, cujo sonho tem um sentido a ser explicitado pela fala do sonhador. Nesse contexto, caberia ao analista escutar o relato, tomado como descrição e análise do sonho, e buscar na fala do paciente a realidade contextual. No entanto, na articulação metapsicológica, Freud toma o sonho no campo dos processos psíquicos em uma referência direta ao aparelho psíquico, trazendo com tal proposição pequenos problemas conceituais, tais como a transcrição ou tradução de representações, a vinculação entre inconsciente e 
memória, a direção do aparelho psíquico; ou seja, questões derivadas da superposição de elementos conceituais e empíricos (Cf. AIRES, 2005).

Nesse sentido, talvez possamos afirmar que a teoria presente na prática psicanalítica, a interpretação clínica dos sonhos, não depende diretamente dos conceitos da metapsicologia. Dito de outro modo: um sonho pode ser interpretado - bem como qualquer outra formação do inconsciente - tomando os elementos contextuais da vida particular do sonhador, mas apenas na condição de construir uma teorização sobre a posição do sujeito que leve em conta a dimensão de endereçamento presente na narrativa de cada sonho. De certa forma, podemos afirmar que Freud só poderia escrever a Traumdeutung a partir de seus próprios sonhos, em um endereçamento a Fliess (Cf. MASSON, 1986) ou ao leitor de seu texto. Nos sonhos de pacientes que ele acompanhou em suas cadeias associativas, Freud lida com o endereçamento, na condição daquele que acolhe a narrativa de um outro para ele, esse estranho médico que se dedica a interpretar sonhos. Então, nesse contexto, torna-se possível retornar ao início: considerar a leitura da bibliografia produzida sobre os sonhos como um recorte desse fenômeno; atribuir a este uma condição psíquica e prenhe de sentido; apresentar ao leitor, por meio de certas estratégias, um texto que o implica, ele Freud, mas, também, que implica o leitor, como sonhador/intérprete/censor de sonhos. Talvez por isso essa seja uma das obras mais lidas de Freud, obra que transforma o leitor em intérprete em potencial de seus próprios sonhos ou, ainda, na condição de analista, do sonho de cada paciente recebido a cada vez como se fosse a primeira. Novo início na relação entre interpretandum e interpretans.

\section{Referências}

AIRES, S. O inconsciente depois de Lacan: temporalidade e significação. Revista de Filosofia Aurora, v. 17, n. 20, p. 165-184, 2005.

BORGES, J. L. O conto policial. In: BORGES, J. L. Borges oral. Lisboa: Veja, [19--]. 
FOUCAULT, M. Um diálogo sobre os prazeres do sexo: Nietzsche, Freud e Marx. São Paulo: Landy, 2000.

FREUD, S. A interpretação dos sonhos. In: FREUD, S. Obras psicológicas completas de Sigmund Freud. Rio de Janeiro: Imago, 1977. v. 4-5. Publicado originalmente em 1900.

FREUD, S. Construções em análise. In: FREUD, S. Obras psicológicas completas de Sigmund Freud. Rio de Janeiro: Imago, 1977. v. 23. Publicado originalmente em 1937.

GAY, P. Freud: uma vida para nosso tempo. Tradução de Denise Bottman. São Paulo: Companhia das Letras, 1989.

GINZBURG, C. Sinais: raízes de um paradigma indiciário. In: GINZBURG, C. Mitos, emblemas, sinais. São Paulo: Companhia das Letras, 1990.

MASSON, J. M. A correspondência completa de Sigmund Freud para Wilhelm Fliess (1887-1904). Tradução de Vera Ribeiro. Rio de Janeiro: Imago, 1986.

POLITZER, G. Crítica dos fundamentos da psicologia: a psicologia e a psicanálise. Piracicaba: UNIMEP, 1998.

RICOEUR, P. De l'interprétation: essai sur Freud. Paris: Seuil, 1965.

Recebido: 20/06/2011

Received: 06/20/2011

Aprovado: 22/07/2011

Approved: 07/22/2011 